\title{
Uma experiência de aplicação da teoria dialógica no ensino-aprendizagem de língua latina em um curso de Letras
}

An application experience of the dialogic theory in the teaching/learning of the Latin language in a Language and Literature Undergraduate Course

Francisco de Freitas Leite*

Universidade Regional do Cariri

Crato, Ceará / Brasil

Maria Margarete Fernandes de Sousa**

Universidade Federal do Ceará

Fortaleza, Ceará / Brasil

\begin{abstract}
RESUMO: Este artigo apresenta os resultados de uma pesquisa aplicada da teoria dialógica para a inovação/atualização do ensino-aprendizagem de língua latina, realizada no período letivo 2015.1, com quatro turmas do curso de Letras da Universidade Regional do Cariri, Ceará. O plano metodológico segue a orientação dialógica de estudo da língua ancorado na sua realidade de uso, isto é, a partir de enunciados concretos considerados em sua inserção histórica, ideológica e sociocultural. Os resultados obtidos demonstram que a teoria dialógica representa, sim, uma alternativa teórico-metodológica exequível, cuja aplicação promove ganhos heurísticos para a inovação e/ou atualização do ensino-aprendizagem de língua latina, sobretudo, em termos de aumento de interesse dos estudantes e da própria compreensão deles acerca da finalidade do estudo do latim.
\end{abstract}

PALAVRAS-CHAVE: Concepção dialógica da linguagem; Latim; Didática; Ensino superior.

*freitas_leite@hotmail.com

**margarete.ufc@gmail.com 


\begin{abstract}
This paper presents the results of an applied research in dialogic theory meant to innovate and update the teaching/learning process of Latin language. The research was executed in the school year 2015.1 with four classes of the Language and Literature Undergraduate Course at Regional University of Cariri, Ceará. The methodological planning is based on dialogic oriented language studies that attach the language to the reality of its use, i.e., concrete enunciates considered in their historical, ideological, and sociocultural insertion. The results show that the dialogic theory does represent a feasible theoreticalmethodological alternative, whose application promotes heuristic gains for innovation and/or update of teaching/learning Latin language, especially in terms of increasing the students interest and understanding of the purpose of studying Latin.
\end{abstract}

KEYWORDS: Dialogic conception of language; Latin; Didacticism; Higher education.

\title{
Introdução
}

É grande a quantidade de trabalhos (livros, capítulos de livros, teses, dissertações, monografias e artigos) no Brasil e no exterior que tematizam, direta ou indiretamente, diversas questões relacionadas ao ensino-aprendizagem da língua latina. Destacamos a seguir alguns estudos que usamos, durante nossa pesquisa, para cotejar diferentes experiências concernentes ao ensino de latim.

Dos trabalhos com foco sobre a temática do léxico, primeiro citamos o capítulo de livro de Arruda (2010), que aborda, apoiado também na teoria da multimodalidade, questões pedagógicas relativas ao uso do dicionário no ensino de latim e, segundo, a dissertação de Longo (2006), que, baseada teoricamente em pressupostos da Linguística Estruturalista, discute os problemas impostos pelo dicionário de latim ao ensino inicial desse idioma.

Alguns trabalhos têm como ponto de convergência a ênfase sobre questões de tradução. Entre esses, podemos mencionar (I) a dissertação de Fernandes (2010), que descreve e analisa manuais que se propõem a ensinar a tradução e a gramática do latim, com o objetivo principal de reconhecer suas características e verificar possíveis semelhanças e diferenças entre eles e (II) o livro de Lima (1995), em que são abordados - com elementos teóricos da Linguística Estruturalista, da Semiótica, da Teoria Literária e da Tradutologia - problemas, tais como os concernentes ao binômio língua/ literatura, relativos a alguns métodos de ensino do latim para principiantes adultos em cursos de Letras. 
Outros trabalhos, apesar de publicados em épocas diferentes, como o livro de Faria (1959) e a monografia de Heck (2013), aproximam-se por abordar problemas antigos, tais como os de método, relacionados ao desinteresse em se estudar o latim. O primeiro deles, uma obra didática já tida como clássica entre latinistas brasileiros, trata de finalidades e experiências do/no ensino de latim no Brasil e em outros países; o segundo deles problematiza o motivo do abandono do ensino de latim no Brasil e propõe o resgate deste ensino para a formação de jovens e preparação de adultos para a vida profissional.

Vários trabalhos, por fim, são os que adotam propostas didáticas diferentes para o ensino-aprendizagem da língua latina, mas que se assemelham por seus aportes (a propósito, atualizados) na Linguística Aplicada. Entre esses, damos destaque (I) ao livro didático de Jones e Sidwell (2012), que usa o método Reading Latin (de Cambridge) no ensino da língua latina, a partir de textos inseridos em seu contexto histórico-cultural; (II) ao artigo de Maranhão (2009), que traz uma crítica à ênfase no ensino do latim com base em estrutura morfossintática, no léxico e na prática da tradução de sentenças descontextualizadas e de (fragmentos de) textos, em detrimento do estudo sócio-histórico da língua latina; (III) ao artigo de Oliveira (2014), que tematiza propostas para a adequação do ensino do latim à realidade sociocultural de nossos dias e, consequentemente, para a melhoria de sua prática didática; (IV) ao artigo de Quednau (2011), que discute métodos de ensino-aprendizagem de latim e questões de aquisição da língua latina, sobretudo, a partir da obra Lingua Latina per se illustrata, de Hans Ørberg; e (V) à dissertação de Mioti (2006), em que são abordadas questões relativas às perspectivas do ensino de latim para o nível superior, aos pressupostos linguísticos e culturais que animam o método e ao papel da língua materna na aprendizagem de uma língua "estrangeira", observadas as particularidades que distinguem as línguas clássicas das vernáculas.

Esses trabalhos trazem diferentes perspectivas teóricas (todas pertinentes), nenhuma delas, porém, atrelada a uma visão dialógica. A revisão que fizemos deles serviu também para que pudéssemos comprovar que a maioria das pesquisas sobre ensino de latim baseia-se em perspectivas não enunciativas da língua e que, portanto, uma pesquisa como a nossa, com base em uma perspectiva teórica discursiva, tem ares de ineditismo e a relevância de testar uma nova possibilidade para a inovação do ensinoaprendizagem da língua latina. 
Extensa também é a lista de trabalhos que, no todo ou em partes, tratam de questões relativas à educação e ao ensino-aprendizagem de línguas em perspectiva dialógica. Consideramos a seguir alguns destes trabalhos aos quais recorremos em nossa pesquisa.

Dos artigos científicos que nos permitiram examinar procedimentos e atividades didáticas plausíveis de ensino-aprendizagem de língua por um viés dialógico, damos destaque (I) ao de Angelo e Menegassi (2014), que aborda a construção de perguntas de leitura na prática docente em uma Sala de Apoio à Aprendizagem de Língua Portuguesa (SAALP) $-6^{\circ}$ ano do Ensino Fundamental, na região centro-sul do estado do Paraná e trata da orientação e do acompanhamento à prática de um professor de SAALP na elaboração de perguntas de leitura, a partir dos conceitos relacionados ao dialogismo do Círculo de Bakhtin e das contribuições da Linguística Aplicada; (II) ao artigo de Almeida e Leite (2013), que tematiza a relevância de ser dado destaque à relação intrínseca entre a linguagem e seu meio sociocultural para a superação de problemas relacionados a aulas de linguagem e, especificamente, a aulas de português no contexto do sertão cearense; (III) ao artigo de Puzzo (2012), em que é discutida a questão da gramática e do ensino (especificamente quanto ao emprego da pontuação no texto literário) numa perspectiva discursiva; (IV) ao artigo de Sobral (2010), em que é defendida a ideia de que ensinar gêneros é mostrar o que são e como funcionam os gêneros, quais os projetos enunciativos a que servem, recorrendo a vários tipos de textualidades, em sua existência concreta, ao passo que transmitir gêneros é deixar de lado os projetos enunciativos, que são o que os distingue dos textos que servem a seus propósitos e, assim, transformá-los em rígidas formas textuais; e (V) ao artigo de Zozzoli (2012), que reflete sobre a contribuição da noção de compreensão responsiva ativa para o ensino de línguas e para o ensino de forma geral, utilizando uma experiência vivenciada com pesquisas e trabalhos orientados desde 1995, no quadro do Grupo de Pesquisa do Conselho Nacional de Desenvolvimento Científico e Tecnológico (CNPq) Ensino e aprendizagem de línguas, nos quais essa noção é articulada com outras e com outros saberes relativos ao ensino e à aprendizagem.

Dos livros que, no todo ou em alguns capítulos, nos auxiliaram a ponderar sobre possibilidades de equacionar problemas relacionados à adequação de uma orientação dialógica para um método de ensino de língua, citamos o de Geraldi (2010), em que estão reunidos diversos trabalhos 
do autor (muitos deles fundamentados em pressupostos bakhtinianos) em torno de questões relativas à aprendizagem da língua materna e às contribuições que o processo de ensino pode a ela oferecer; o capítulo de Possenti (2009), que aborda a questão dos gêneros discursivos no tocante à sua utilização no campo pedagógico; e, por fim, o livro de Bakhtin (2013), que apresenta questões fundamentais a respeito do ensino de língua, a partir da experiência e das práticas pedagógicas do Bakhtin professor, e que esclarece muitos pontos sobre a "relação constitutiva entre metodologia e teoria no pensamento bakhtiniano” (BRAIT, 2013, p. 17).

Embora esses trabalhos tratem, numa perspectiva dialógica, de questões voltadas à educação e ao ensino-aprendizagem de línguas, mas não especificamente de latim, nada impede de serem usados/adaptados (como procuramos fazer nesta pesquisa) no tratamento de questões relativas ao ensino-aprendizagem de língua latina.

É pequena, todavia, a quantidade de trabalhos que abordam especificamente questões relacionadas ao ensino-aprendizagem da língua latina na perspectiva da teoria dialógica. Alguns desses poucos trabalhos que conhecemos são o artigo de Freitas (2012), que apresenta a análise de Lingua Latina per se illustrata, escrita por Hans Ørberg na década de 1990, a partir de pesquisas sobre o ensino de línguas; o artigo de Leite (2011), que considera expressões latinas em cartas pessoais, abordando-as como enunciações dotadas de sentido contextualizado e não como "frases" ou "palavras" a serem simplesmente "traduzidas"; e, por fim, o livro de Santos Silva e Leite (2012), que trata do ensino de latim e suas dificuldades no tempo presente e, com base em conceitos bakhtinianos, ressalta o valor de uma abordagem do latim que o perceba em sua natureza comunicativa.

Desses trabalhos, destacamos a ênfase dada à compreensão (com a qual nos coadunamos) de que o ensino-aprendizagem do latim pode extrapolar o nível gramatical e alargar-se em considerações sobre os elementos socioculturais, históricos e ideológicos presentes nos usos concretos da língua.

Este presente artigo - que se insere na linha de trabalhos voltados a tratar de questões de ensino do latim por um viés dialógico - apresenta os resultados de uma pesquisa ${ }^{1}$ que realizamos, durante o período letivo

\footnotetext{
${ }^{1}$ Intitulada a princípio $O$ dialogismo como uma alternativa teórico-metodológica para a inovação/ atualização do ensino-aprendizagem de língua latina em curso de Letras.
} 
2015.1 - contando com a participação de 120 estudantes $^{2}$ de duas turmas da disciplina Língua Latina I e duas da disciplina Língua Latina II (ofertadas, respectivamente, no primeiro e no segundo semestre) do curso de Letras da Universidade Regional do Cariri (URCA), nas cidades de Crato e de Várzea Alegre, Ceará -, com o objetivo de testar a exequibilidade e a heurística da aplicação da teoria dialógica para a inovação/atualização do ensinoaprendizagem de língua latina em cursos de Letras.

Partindo do entendimento de que (i) o ensino de latim com base somente no léxico e nas regras do sistema abstrato da língua é, diante dos avanços das pesquisas linguísticas, antiquado e contribui ainda mais para reforçar aquela compreensão que muitos têm do estudo do latim como algo despropositado e (ii) de que a finalidade das disciplinas de latim num curso de Letras (com licenciatura em português e outras línguas modernas) não é formar latinistas, mas contribuir (sobretudo, em termos de domínio básico da língua latina e da compreensão da sua importância na constituição de nossa cultura ocidental e das línguas românicas) para a formação acadêmicohumanística dos futuros profissionais das Letras, decidimos experimentar ações concretas de inovação/atualização do ensino-aprendizagem de latim em curso(s) de Letras.

Optamos por nos orientar nesta pesquisa pela teoria dialógica por sua propensão de considerar as línguas nunca uma circunscrição estritamente endógena ou puramente imanentista, mas sempre a partir de sua realidade concreta e inerentemente social, ideológica, histórica e cultural, o que, a nosso ver, representa uma alternativa teórica inovadora para o ensinoaprendizagem do latim.

Este trabalho está pautado nessa linha de raciocínio e a perspectiva de contribuirmos para uma nova possibilidade didática de estudos do latim sustenta nossa motivação.

Passemos à apresentação da organização das seções que se seguem a esta seção introdutória. Na seção 1 deste artigo, discorremos com mais detalhes acerca da orientação teórico-metodológica dialógica que delineamos para nossa pesquisa sobre ensino-aprendizagem de língua latina no curso de Letras da URCA. Na seção 2, consideramos alguns aspectos da aplicação dos

\footnotetext{
${ }^{2}$ Todos esclarecidos de que suas participações nas aulas, seus exercícios e suas avaliações seriam analisados para os fins específicos desta pesquisa, devidamente aprovada pelo Comitê de Ética em Pesquisa da URCA, conforme CAAE 44452615.6.0000.5055 e Parecer 1.054.240 da Plataforma Brasil.
} 
fundamentos da teoria dialógica nas aulas das disciplinas Língua Latina I e Língua Latina II deste mesmo curso, dando destaque às atividades didáticas e paradidáticas implementadas e à participação dos estudantes nelas. $\mathrm{Na}$ seção 3, concluímos este artigo destacando os resultados obtidos, dando ênfase aos ganhos heurísticos da aplicação da teoria dialógica à atualização do ensino-aprendizagem da língua latina nos cursos de Letras.

\section{A orientação teórico-metodológica dialógica delineada para a pesquisa sobre ensino-aprendizagem de língua latina}

$\mathrm{Na}$ concepção de linguagem do Círculo de Bakhtin, o diálogo e a produção de sentido são entendidos como princípios básicos de qualquer ato de linguagem discursiva, de modo que, em uma pesquisa que se oriente por essa concepção (como esta nossa sobre ensino-aprendizagem de língua latina), o foco não são formas linguísticas descontextualizadas, e sim, enunciados concretos, que são produzidos por sujeito(s) e que se destinam a outro(s) sujeito(s).

Nesse sentido, em termo da teoria dialógica, nenhuma língua é neutra, pois há sempre valores humanos associados a seus usos. Por este ponto de vista teórico, estudar qualquer língua apenas no nível estrutural pode ocasionar uma falsa impressão de sua neutralidade e contra esse perigo é relevante basear o estudo em enunciados concretos, estes que são plenos de pensamentos, sentidos e significados dos homens (BAKHTIN, 2011a).

Quando, porém, o pesquisador se propõe a trabalhar com essa concepção de linguagem e precisa passar da teoria à prática, outras questões são apresentadas como desafiadoras. Consideremos a seguir algumas das questões que nos acercaram.

A concepção dialógica da linguagem do Círculo de Bakhtin não constitui um modelo rigidamente formalizado de investigação científica, visto que, como destaca Faraco (2009, p. 40): "ao percorrermos os textos do Círculo de Bakhtin não nos deparamos, em nenhum momento, com a formalização de método científico propriamente dito, mas com grandes diretrizes para construirmos um entendimento mais amplo das realidades sob estudo".

Orientar uma pesquisa pela concepção de linguagem do Círculo de Bakhtin significa pautar-se por princípios teóricos e filosóficos que não correspondem a categorias científicas propriamente ditas nem fixam modelos rígidos de aplicação. As especificidades do objeto a ser investigado, 
todavia, deverão ser percebidas pelo pesquisador com a sensibilidade e astúcia de quem dialoga com um objeto que não é mudo para que a este objeto e aos fins da pesquisa seja conformada a metodologia de investigação em perspectiva teórico-filosófica dialógica, como podemos ver em Angelo e Menegassi (2014), Puzzo (2012) e Sobral (2010), para citarmos apenas três exemplos do que seja, segundo Brait (2010, p. 29, grifo da autora), "a postura dialógica diante do corpus discursivo, da metodologia e do pesquisador".

Sobre a postura dialógica que um pesquisador da área das Ciências Humanas deve ter, pela própria natureza do objeto (sujeito) com que interage, diz Bakhtin (2011b, p. 400, grifo do autor):

Qualquer objeto do saber (incluindo o homem) pode ser percebido e conhecido como coisa. Mas o sujeito como tal não pode ser percebido e estudado como coisa porque, como sujeito e permanecendo sujeito, não pode tornar-se mudo; consequentemente, o conhecimento que se tem dele só pode ser dialógico.

Nessa concepção, o pesquisador de Ciências Humanas (um linguista, por exemplo) não pode negligenciar que um estudo de linguagem significa também a percepção de que onde há língua, texto, discurso e enunciação há sujeitos em interação, que devem ser levados em consideração.

Passemos, na sequência, a tratar de questões de metodologia sob o ponto de vista da teoria dialógica.

Baseamos a orientação metodológica adotada em nossa pesquisa na seguinte ordenação metodológica para o estudo da língua proposta de Bakhtin/Volochínov (2009, p. 129):

1. As formas e os tipos de interação verbal em ligação com as condições concretas em que se realiza.

2. As formas das distintas enunciações, dos atos de fala isolados, em ligação estreita com a interação de que constituem os elementos, isto é, as categorias de atos de fala na vida e na criação ideológica que se prestam a uma determinação pela interação verbal.

3. A partir daí, exame das formas da língua na sua interpretação linguística habitual.

De acordo com essa proposta de ordem metodológica, um estudo de uma língua é feito com base na sua realidade (em oposição à potencialidade), o que significa levar em consideração o enunciado concreto em seu 
contexto histórico, ideológico e sociocultural de produção, circulação e recepção (que pressupõe a consideração de sujeitos em interação e os fins da enunciação, por exemplo) e o gênero do discurso (em sua relação íntima com determinadas esferas da atividade humana) ${ }^{3}$ a que o enunciado pertença, para, enfim, serem realizadas as análises linguísticas.

Seguindo essa diretriz de base dialógica, traçamos, em nossa pesquisa, um planejamento metodológico para a condução das aulas, no período 2015.1, das disciplinas Língua Latina I e Língua Latina II que fazem parte do currículo mínimo comum às duas habilitações (I. Português e Literaturas de Língua Portuguesa e II. Língua Portuguesa e Língua Inglesa com as respectivas literaturas) do curso de Letras da URCA.

Nosso planejamento metodológico procurou contemplar as ementas das disciplinas e seus conteúdos programáticos dentro da carga-horária prevista, a saber:

Língua Latina I (72 horas-aulas) - Ementa: Introdução ao universo linguístico-cultural da Roma Antiga. Domínio da morfologia e sintaxe básicas da língua latina. Conteúdo programático:

- História externa da língua latina.

- Pronúncias do latim. Alfabeto latino. Quantidade das sílabas.

- As categorias gramaticais do latim.

- A estrutura da frase latina.

- As declinações e suas características temáticas.

- Gêneros e número dos nomes.

- Substantivos da $1^{a}$ e da $2^{a}$ declinação.

- Adjetivos de $1^{a}$ classe.

- O verbo irregular esse.

- Verbos regulares: as 4 conjugações - voz ativa.

- Introdução ao uso das preposições, dos advérbios e das conjunções.

Língua Latina II (72 horas-aulas) - Ementa: Estudo da língua latina a partir do trabalho com textos originais antigos, medievais ou contemporâneos. Conteúdo programático:

\footnotetext{
3 “As 'esferas de atividade' são entendidas no círculo de Bakhtin como 'regiões' de recorte sócio-histórico-ideológico do mundo, lugar de relações específicas entre sujeitos, e não só em termos de linguagem. São dotadas de maior ou menor grau de estabilização a depender de seu grau de formalização, ou institucionalização, no âmbito da sociedade e da história, de acordo com as conjunturas específicas" (SOBRAL, 2006, p. 8).
} 
- Verbos: tempos primitivos e derivados; introdução à voz passiva (perfectum e infectum); compostos do verbo esse.

- Substantivos da $3^{\mathrm{a}}$, da $4^{\mathrm{a}}$ e da $5^{\mathrm{a}}$ declinação.

- Adjetivos de $2^{a}$ classe.

- Graus dos adjetivos.

- Pronomes pessoais, possessivos e demonstrativos.

Programamos que os conteúdos das disciplinas fossem trabalhados com os estudantes a partir de enunciados concretos pertencentes a gêneros do discurso variados e de diferentes épocas e lugares. Concomitantemente ao estudo gramatical, planejamos que fossem realizadas leituras de textos e pesquisas sobre o contexto histórico, ideológico e sociocultural de produção, circulação e recepção dos enunciados. E, ainda, que sempre fossem feitas preleções sobre os gêneros do discurso utilizados nas aulas para auxiliar os estudantes no processo de construção de sentido dos enunciados estudados.

Planejamos também que os conteúdos programáticos das duas disciplinas seriam trabalhados com enunciados antigos, medievais e contemporâneos, com atenção voltada também às práticas sociais e culturais relacionadas às singularidades dos vários latins e de seus usos específicos: latim literário, latim vulgar, latim eclesiástico, latim bárbaro, latim macarrônico, latim de missa, latim de cozinha, latim jurídico, latim diplomático, latim científico etc.

Para a disciplina Língua Latina I, a programação dos gêneros discursivos a serem utilizados nas atividades de preleção dos conteúdos, nos exercícios e nas avaliações previa a utilização de sentença proverbial, epitáfio, poesia lírica, prece, aforismo jurídico e epígrafe, com preferência por enunciados breves, mas que servissem ao propósito de proporcionar aos estudantes uma introdução à morfossintaxe básica da língua latina a partir de usos concretos.

Para a disciplina Língua Latina II, a programação dos gêneros discursivos a serem utilizados nas atividades didáticas envolvia epigrama, grafito, hino religioso, legenda de gravura, carta e telegrama, a partir dos quais poderia ser aprofundado o estudo da morfossintaxe da língua latina e de outras questões relacionadas, por exemplo, ao papel do latim na formação/constituição da nossa cultura ocidental.

Outras ações subsidiárias (ou paradidáticas) planejadas e praticadas para favorecer o ensino-aprendizagem da língua latina foram: 
1. o incentivo à participação dos estudantes, como bolsistas e como voluntários, em programas de iniciação científica com pesquisas de temáticas sobre o latim;

2. a produção e publicação de exemplares xerocopiados de um boletim didático-informativo com pequenas matérias relacionadas aos temas estudados em sala de aula para circulação interna no curso de Letras.

Utilizamos também recursos multimídia (notebook, datashow, caixa de som etc.), várias semioses (tais como imagem, som, vídeo etc.) e a internet para dinamizar as aulas, facilitar os estudos intersemióticos e para desmistificar a visão de alguns estudantes de que aula de latim é maçante e desatualizada.

\section{A aplicação da teoria dialógica nas aulas de língua latina}

No cerne de nossa proposta de aplicação dos fundamentos da teoria dialógica nas aulas de língua latina, estava a compreensão de que "quando isolada dos aspectos semânticos e estilísticos da língua, a gramática inevitavelmente degenera em escolasticismo" (BAKHTIN, 2013, p. 23). Nossa proposta, nesse sentido, era a de que o estudo gramatical do latim não deveria ser desgarrado de outras questões que organicamente estão envolvidas nos usos concretos das línguas: questões ideológicas, históricas, socioculturais, emotivo-volitivas e estilísticas, por exemplo, de modo que nossas atividades didáticas não deveriam ser baseadas em textos "recortados, adaptados ou artificialmente construídos para público infanto-juvenil da época em que ainda se ensinava latim na escola" (MARANHÃO, 2009, p. 29).

Em termos da teoria dialógica, diversas questões de linguagem só podem ser devidamente tratadas quando consideradas na realidade da vida dos homens; por exemplo, os elementos estruturais de uma língua (tanto faz se latim, português, inglês etc.) não são em si e por si, ou seja, imanentemente, austeros, elitistas, racistas, segregadores etc.; esses valores são socioculturais, portanto, só existem na linguagem discursiva do mundo tangível, não em uma abstração linguística. Dessa forma, só podem ser levados em conta por uma perspectiva que considere a língua em enunciados concretos, jamais em frases hipotéticas (LEITE, 2014).

Passamos, a seguir, a considerar pormenores concernentes à pesquisa em que experimentamos a aplicação dos fundamentos da teoria dialógica nas aulas das disciplinas Língua Latina I e Língua Latina II no período e universidade em questão. 
Nas aulas, em que falamos sobre tradução, procuramos sempre ressaltar que não trabalharíamos com a ideia de se fazer "a" tradução, e sim, "uma" tradução aproximada, com ênfase na noção de construção de sentido - posto que sentido é uma construção (porque envolve interação, interpretação etc.) e não um achado (isto é, não é algo que se ache no texto per se). Em se tratando da teoria dialógica, não se considera o sentido sem levar em conta o enunciado concreto e a enunciação, que, por conseguinte, significa a consideração do gênero do discurso, porque, como diz Medviédev (2012, p. 198), "pensamos e compreendemos por meio de conjuntos que formam uma unidade: os enunciados. Já o enunciado, como sabemos, não pode ser compreendido como um todo linguístico, e suas formas não são sintáticas". É nessa concepção que o Círculo de Bakhtin entende que não há sentido em oração ou palavra como unidades da língua-sistema; nelas há potencialidades de sentido que só se concretizam em enunciados que são produzidos em determinados gêneros.

Nas aulas da disciplina Língua Latina II, realizamos estudos a partir de enunciados concretos produzidos entre os séculos I a.C. e V da Era Cristã, período em que o latim era uma língua viva da comunicação discursiva de populares (em geral, em sua variedade dita sermo unlgaris) e de eruditos (em geral, em sua variedade dita sermo classicus) no mundo romano. Realizando atividades com grafitos pompeianos antigos, além das questões gramaticais, tratamos de estilos populares, de expressividade poética, de peculiaridades do latim vulgar (sermo plebeius) e da natureza verbo-visual comum a vários enunciados pertencentes ao gênero grafito, como é o caso deste reproduzido a seguir: 
Figura 1: Grafito pompeiano antigo

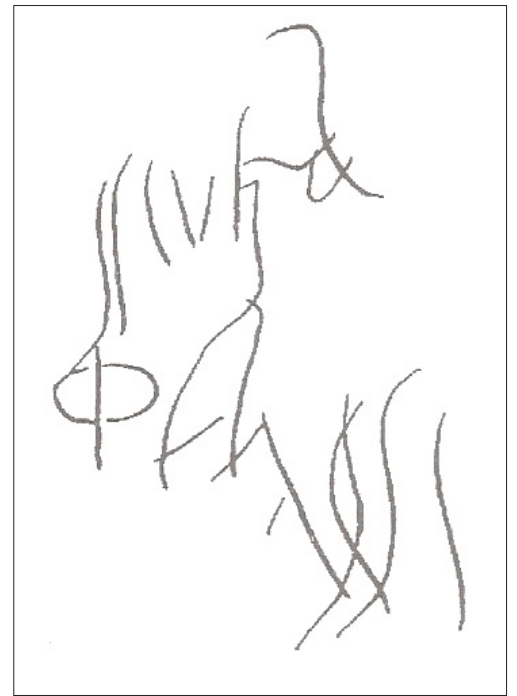

Fonte: Funari (2003, p. 118)

Pedimos aos estudantes que analisassem este grafito e pensassem não só em uma tradução, mas que o interpretassem, considerando seu caráter verbo-visual e seus traços de poeticidade popular participantes do processo de construção de sentido.

Foi preciso que chamássemos atenção dos estudantes para algumas peculiaridades da grafia das palavras motivadas pela configuração do desenho, para o uso da letra grega $\varphi$ (em vez da letra latina $f$ ) à semelhança de uma cabeça humana e para as repetições da letra $s$ que "produz um efeito sonoro sibilante que remete ao alongamento da emissão" (FUNARI, 2003, p. 120) e como que simulam iconicamente movimentos de braço e pernas; mas não foi difícil para que eles interpretassem o grafito, com seu tom libidinoso, como algo que produz sentidos para além do que "fala" o texto (transcrito como: sseuera yelassss) ou uma tradução aproximada (tal como: "Severa, chupas").

Em outras aulas dessa mesma disciplina, usamos algumas gravuras medievais e renascentistas com legendas em latim para falar da relação intrínseca (não necessariamente icônica, como no caso do grafito anteriormente tratado) que o enunciado verbal muitas vezes mantém com outras semioses, tais como com a pintura, de modo que traduzi-lo descontextualizadamente resulta em efeito de sentido limitado (se não vago) 
em relação ao efeito de sentido que pode ser construído quando considerado o enunciado em seu contexto de produção.

Uma das gravuras com a qual trabalhamos está reproduzida a seguir, conhecida como Sawing Boards (from the Infancy of Christ series) [em português: Serrando tábuas (da série A infância de Cristo)].

Figura 2: Gravura Sawing Boards (from the Infancy of Christ series)

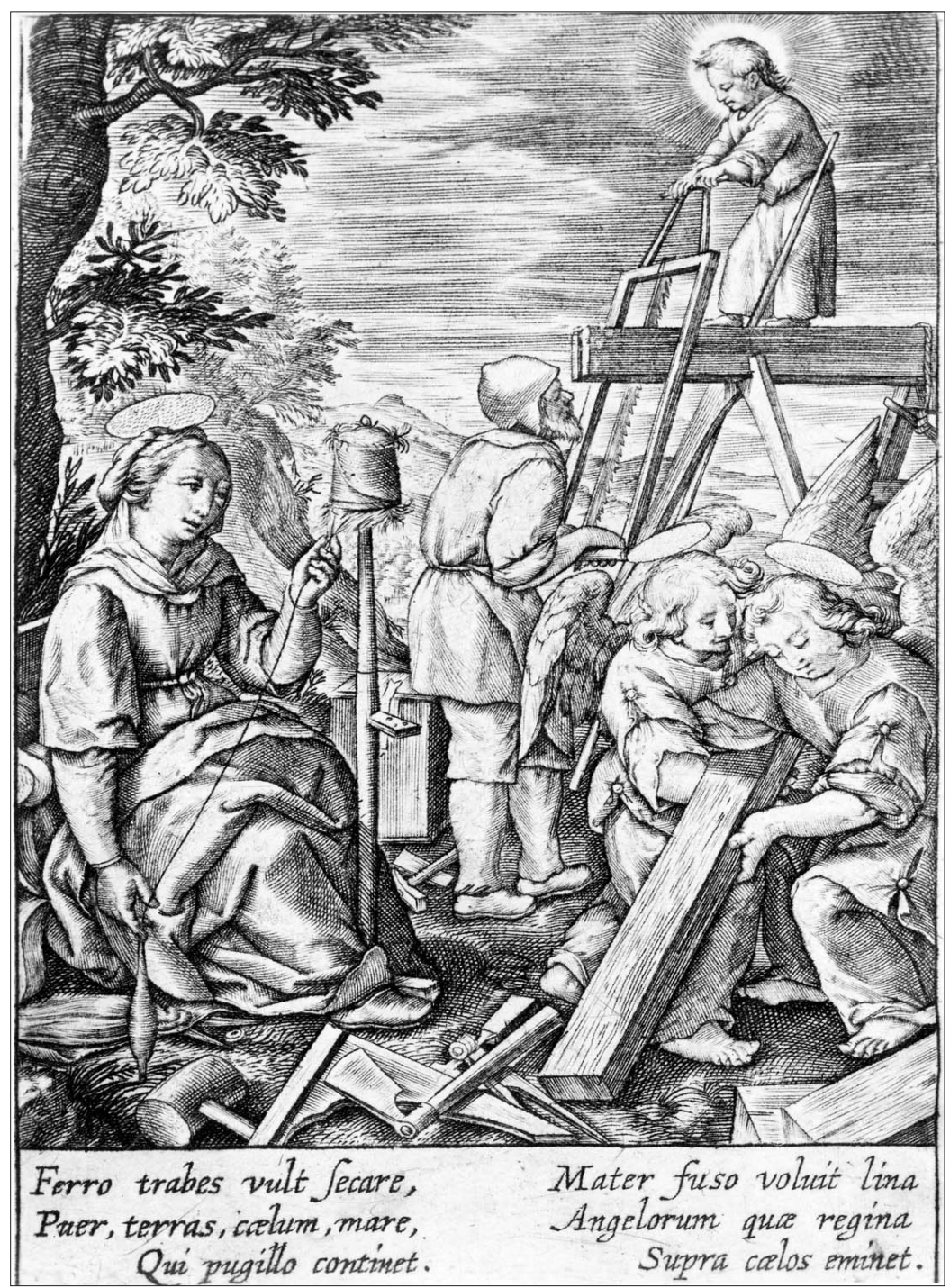

Fonte: Wierix (s/d) 
Discutimos sobre como seria uma tradução do texto "Ferro trabes vult secare, / Puer, terras, caelum, mare, / Qui pugillo continet. / Mater fuso voluit lina / Angelorum quae regina / Supra caelos eminet" (transcrito da gravura) se fosse desconhecida sua relação intrínseca com a ilustração de um episódio da vida do menino Jesus. Pensamos que o substantivo ferro (no nominativo singular: ferrum) poderia ser traduzido simplesmente como "ferro" ou "qualquer instrumento de ferro"; puer poderia ser traduzido simplesmente como "menino", ou "um rapaz" ou "filho"; regina, como "rainha", ou "princesa" e nenhuma dessas acepções (como potencialidades de sentido) expressaria a singularidade do valor que essas palavras ganham no contexto da gravura: uma serra (e não qualquer instrumento de ferro), o menino Jesus (e não um menino qualquer) e a Rainha do Céu (ou seja, não uma rainha indefinida, mas a Regina (oeli).

Convidamos os estudantes a pensarem que:

Em determinados textos ou conjuntos de textos, artísticos ou não, a articulação entre os elementos verbais e visuais forma um todo indissolúvel, cuja unidade exige do analista o reconhecimento dessa particularidade. São textos em que a verbo-visualidade se apresenta como constitutiva, impossibilitando o tratamento excludente do verbal ou do visual e, em especial, das formas de junção assumidas por essas dimensões para produzir sentido (BRAIT, 2009, p. 143).

E, em uma atividade coletiva, os estudantes produziram, sob nosso acompanhamento, a seguinte tradução aproximada do enunciado verbal que é parte do todo indissolivel que é a obra de arte Sawing Boards (from the Infancy of Christ series), de Hieronymus Wierix: "Com uma serra, o menino Jesus - que tem na mão as terras, o céu e o mar! - quer (humildemente) cortar as vigas, enquanto Sua mãe - a Rainha que se eleva acima dos céus dos anjos! - enrola (com ternura) os fios de linho num fuso". Tradução esta que, a nosso ver, aproxima-se da ideia, em termos da teoria dialógica, de "compreensão do enunciado (que envolve responsividade e, por conseguinte, juízo de valor)" (BAKHTIN, 2011a, p. 328, grifo do autor).

Em aulas da disciplina Língua Latina I, temos recorrentemente abordado a concepção dialógica de interpretação semântica como necessariamente atrelada à consideração do gênero do discurso e da esfera da atividade humana a que pertença um enunciado. Em uma aula, em que trabalhávamos o conteúdo sobre substantivos da primeira declinação, 
abordamos essa concepção dialógica de interpretação a partir de dois enunciados concretos pertencentes a gêneros diferentes:

O primeiro deles, um epigrama (gênero da esfera artístico-literária), de MARCVS VALERIVS MARTIALIS (em português, Marcos Valério Marcial), epigramatista latino que viveu no séc. I:

Non est, crede mibi, sapientis dicere "Vivam".

Sera nimis vita est crastina: vive hodie.

E o segundo, a prece (gênero da esfera religiosa) "Salve, Regina":

Salve, Regina, Mater misericordiae, vita dulcedo, et spes nostra, salve.

Ad te clamamus exsules filii Hevae.

Ad te suspiramus, gementes et flentes in hac lacrimarum valle.

Eia, ergo, advocata nostra,

illos tuos misericordes oculos ad nos converte.

Et Iesum, benedictum fructum ventris tui,

nobis post hoc exilium ostende.

O clemens, o pia, o dulcis Virgo Maria.

Chamamos atenção dos estudantes para a palavra vita (que ocorre no segundo verso dos dois enunciados) e convidamo-los a pensar: apesar de a palavra latina vita, nos dois enunciados, poder ser traduzida como vida para o português e independentemente de estar no nominativo singular, no primeiro enunciado, e no vocativo singular, no segundo enunciado, quando consideramos os gêneros do discurso e as esferas da atividade humana a que pertencem os dois enunciados, podemos mesmo dizer que, nas duas ocorrências, a palavra vita está carregada semântica e axiologicamente de idênticos valores socioculturais?

Em outras palavras (e em resumo), concluíram os estudantes, em suas interpretações responsivas dos dois enunciados, que vita, no epigrama, está mais próximo da ideia de vida dos prazeres mundanos (típica dos poetas); enquanto que vita, na prece, remete-se a uma espécie de tratamento afetuoso dado à Mãe de Jesus.

Nessa aula sobre substantivos da primeira declinação, estudamos palavras da língua latina sem desgarrá-las da vida (ou das vidas!) dos homens que as utilizam (ou utilizaram). 
De modo geral, procuramos evitar o estudo (inclusive) de morfossintaxe da língua latina baseado em frases (ou estruturas frasais hipotéticas) que não se sabe a que gêneros pertencem. Por exemplo, na disciplina Língua Latina I, nas aulas em que prelecionamos o conteúdo sobre verbos regulares, estudamo-los em provérbios, considerando as características desse gênero do discurso e suas finalidades de uso na Antiguidade e Idade Média (tais como fins didáticos e prescritivos de normas de conduta social).

Um dos provérbios que utilizamos nas aulas foi este: "Sus taciturna vorat, dum garrula voce laborat", que em uma tradução aproximada para o português seria: "a porca silenciosa come, enquanto trabalha com voz loquaz". Destacamos questões morfossintáticas dos verbos - vorat e laborat estão em terceira pessoa singular por concordarem com sus taciturna, ou seja, o sujeito (nominativo singular) -, mas não deixamos de analisar o uso desse provérbio no contexto da Europa medieval, isto é, como alusão "aos modos inconvenientes dos vassalos à mesa” (BRAGANÇA JÚNIOR, 2006, p. 114). Temos, com isso, chamado atenção dos estudantes para que compreendam que o estudo do latim envolve considerar questões de história, ideologia, cultura, sociedade e axiologia e não apenas gramática e literatura.

$\mathrm{Na}$ disciplina Língua Latina II, procuramos dar ênfase ao papel sociocultural, histórico e ideológico da língua latina em contextos de tempo e lugar mais próximos da realidade dos estudantes. Nesse sentido, usamos nas aulas enunciados pertencentes aos gêneros carta e telegrama escritos em latim entre os séculos XIX e XX pelo Padre Cícero Romão Batista e por outros sujeitos do Cariri cearense.

Como exemplo, usamos, em sala de aula, o telegrama enviado por José Marrocos (professor, jornalista e amigo do Padre Cícero), da cidade de Crato (CE), em 27 de maio de 1908, para o Núncio Apostólico (Alessandro Bavona [1856-1912], Núncio no Brasil entre 1908 e 1911) na cidade de Petrópolis (RJ). 
Figura 3: Telegrama em latim

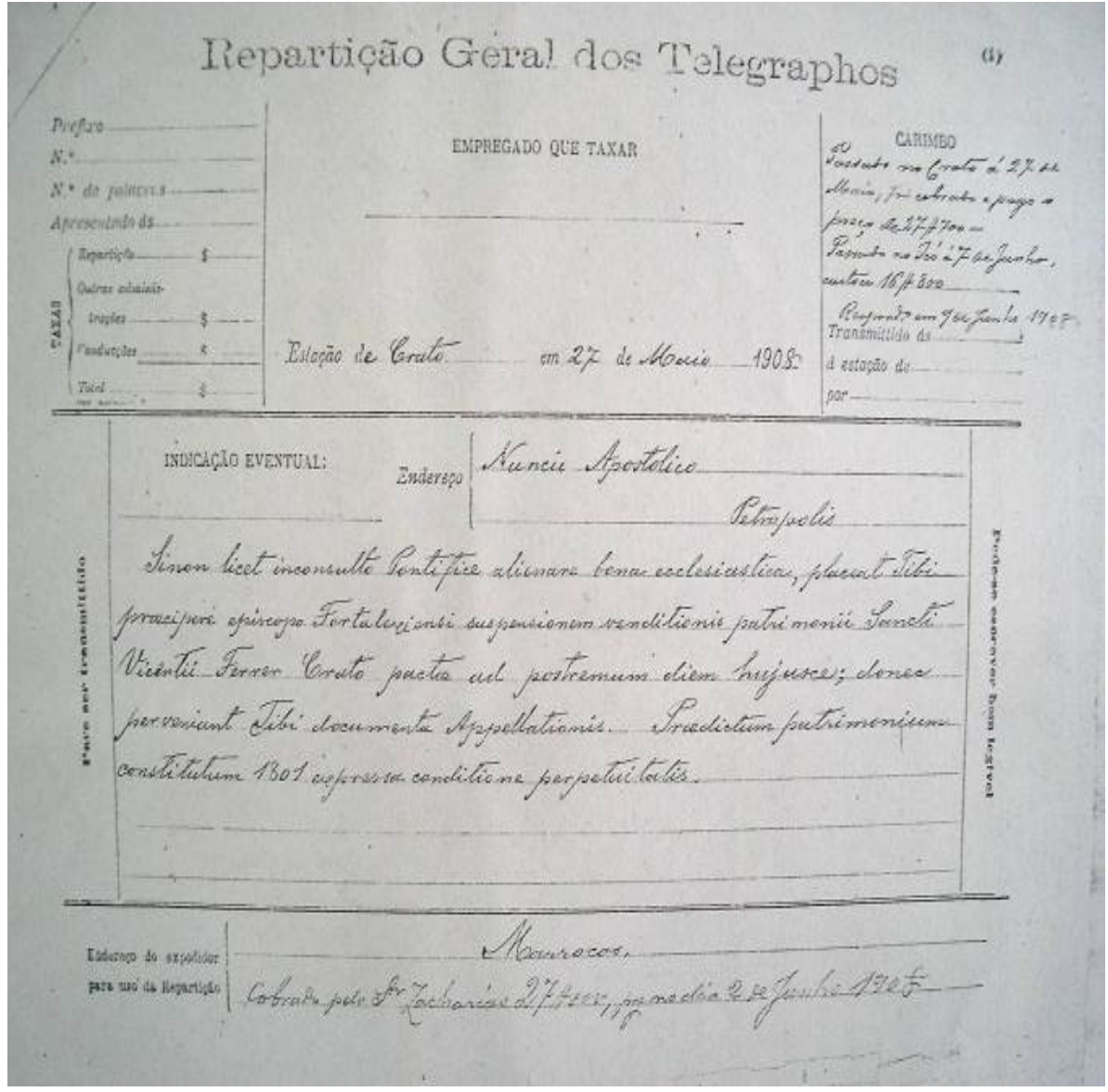

Fonte: Acervo do Departamento Histórico Diocesano Pe. Gomes, Crato-CE.

Estudando esse telegrama, tratamos da relação de proximidade das disciplinas de Língua Latina com as disciplinas de Filologia e de Linguística Histórica e realizamos coletivamente a transcrição textual, que ao final assim ficou:

Nuncio apostolico.

Petropolis

Si non licet inconsulto Pontifice alienare bona ecclesiastica, placeat tibi praecipere episcopo fortalesciensi suspensionem venditionis patrimonii Sancti Vicentii Ferrer Crato pactae ad postremum diem hujusce; donec perveniant 
tibi documenta Appelationis. Praedictum patrimonium constitutum 1801 expressa conditione perpetuitatis.

Nas aulas seguintes, os estudantes produziram também coletivamente, sob nossa supervisão, uma tradução aproximada do texto, conforme reproduzimos a seguir:

\begin{abstract}
Ao Núncio Apostólico
Petrópolis

Visto que não é permitido a um pontífice [um dignitário eclesiástico, por exemplo, um bispo ou um arcebispo] imprudentemente vender os bens da igreja, peço-te, por favor, que ordenes ao bispo de Fortaleza a suspensão da venda do patrimônio [da capela] de São Vicente Ferrer, em Crato, ajustada para o último dia deste presente mês, até que cheguem a ti os documentos da Apelação. O patrimônio supracitado é constituído desde 1801 sob expressa condição de perpetuidade.
\end{abstract}

Utilizando esse telegrama, falamos ainda sobre as letras ramistas ( $v$ e j), abordamos a questão dos neologismos (fortalesciensi), analisamos o valor da partícula ce no pronome demonstrativo hujusce e, concomitantemente a leituras e discussões do texto de Burke (2010) e parte do texto de Leite (2009), realizamos uma atividade em que cada estudante produziu um curto ensaio interpretativo sobre o motivo do uso do latim nesse telegrama, levando-se em consideração o gênero do discurso, a esfera de atividade humana, o autor e o destinatário.

Dessa atividade de produção do ensaio, destacamos certo avanço dos estudantes no que concerne a uma compreensão do latim pós-clássico como uma língua que, no mundo Ocidental, desde a Idade Média, é uma das marcas distintivas de algumas comunidades, tais como a comunidade da Igreja Católica e a dos eruditos (BURKE, 2010).

Além das atividades didáticas em sala de aula, durante o período 2015.1, demos início, com o Programa Institucional de Bolsas de Iniciação Científica (PIBIC) na universidade, a uma pesquisa, também de orientação teórica dialógica, intitulada Inventário linguístico-bistórico e sociocultural das inscrições em latim "perdidas" do Cariri cearense: séculos XVIII, XIX e XX, com a participação de dois estudantes bolsistas e nove estudantes voluntários, com o objetivo de conceber um levantamento minucioso das inscrições 
em latim do Cariri cearense datadas entre os séculos XVIII e XX que já foram destruídas ou que são dadas como "perdidas" (desaparecidas), visando preservar nossa memória e/ou ampliar nosso conhecimento acerca desses bens linguísticos, históricos, sociais e culturais caririenses, cearense e brasileiros.

Essa ligação da pesquisa do PIBIC com a sala de aula tem resultado em um considerável interesse por boa parte dos estudantes (não só dos bolsistas e voluntários) em aumentar seus conhecimentos sobre a presença do latim no contexto do Cariri cearense.

Outro trabalho paradidático que realizamos com os estudantes, durante nossa pesquisa, foi incentivá-los a realizar estudos sobre temáticas abordadas em sala de aula que resultassem em ensaios curtos, resenhas, poemas ou passatempos lúdico-instrutivos que editamos e fizemos circular internamente no curso de Letras da URCA.

Apesar de pequeno o número de estudantes que participaram diretamente deste trabalho paradidático (apenas doze) - pauci sed boni -, consideramos que foram satisfatórios seus resultados, em termos de incentivo à pesquisa, ao trabalho em grupo e à produção acadêmica.

Enfim, foram com ações didáticas e paradidáticas como estas aqui apresentadas que, em nossa pesquisa, experimentamos a aplicação da teoria dialógica nas duas disciplinas de língua latina do curso de Letras, sem limitar o estudo do latim ao meramente textual, gramatical ou lexical, mas ampliando-o às considerações de práticas sociais e culturais que estão atreladas à linguagem discursiva. A seguir apresentaremos as considerações finais da pesquisa.

\section{Conclusão}

Nossa experiência com a aplicação da teoria dialógica nas disciplinas Língua Latina I e Língua Latina II do curso de Letras da URCA tem nos demonstrado que, sem eximir o estudo gramatical, podemos proporcionar aos estudantes que tenham contato com a língua em variadas situações reais de uso para que aos pouco eles formem suas próprias compreensões acerca do latim como elemento constitutivo da cultura ocidental.

Vimos, na prática, que a teoria dialógica favorece que o latim seja estudado não só como uma língua de palavras e desinências, de casos e flexões, pois abre espaço para que o estudo da língua latina vá além da perscrutação de formas e significações estáveis da langue (com sua validade 
geral) e possibilite lucubrar as construções de sentido considerada a linguagem usada no mundo tangível por sujeitos reais em diversos gêneros do discurso e várias esferas da atividade humana ou, nos termos de Bakhtin (2010), que o ensino-aprendizagem do latim não se restrinja à istina (verdade universal) e esteja aberto também ao estudo da pravda (verdade singular) dos enunciados concretos (LEITE, 2014).

Nesse sentido, temos evitado usar aqueles exercícios de conjugação e de declinação com verbos e nomes isolados ou descontextualizados, pois temos observado, na prática, que, mesmo em se tratando de atividades relacionadas à morfossintaxe da língua latina, têm produzido resultados mais satisfatórios (em termos de aumento de interesse dos estudantes e da própria compreensão deles acerca da finalidade do estudo da língua) em estudar o latim dando ênfase a seu aspecto comunicativo a partir de enunciados concretos.

Destacamos que o diálogo - inerente à base filosófica da concepção dialógica da linguagem - que pode ser estabelecido entre as disciplinas de Língua Latina e as de Linguística Histórica, de Filologia, de Paleografia, de Epigrafia e demais disciplinas, inclusive de outras áreas, que, de uma forma ou de outra, abordam aspectos históricos da linguagem é um outro ponto positivo que pode ser incorporado à prática didática como forma de se destacar a relevância e utilidade do conhecimento do latim na área das Ciências Humanas.

Outro ponto que podemos destacar é que o uso de atividades didáticas elaboradas com enunciados em latim mais próximos da realidade dos estudantes (como fizemos com enunciados encontrados no Cariri cearense) desperta neles um interesse maior pelo estudo da língua latina dentro da história e da cultura regional, isto é, a língua percebida dentro de valores situacionais e singulares mais familiares aos estudantes, ou a língua contextualizada em termos de práticas socioculturais que a eles são mais palpáveis.

A adoção de práticas didáticas e paradidáticas que favorecem o gosto pela pesquisa, o raciocínio criativo, a interpretação de valores e verdades singulares, a construção de sentido e a produção de ideias a partir de usos contextualizados da língua latina - em vez da memorização e repetição de conceitos gerais, pontos de vista universais e regras formais - é outro ponto forte que podemos destacar da nossa experiência de aplicação da teoria dialógica para a formação humanística dos acadêmicos de Letras. 
Entendemos que, de um modo geral, a formação acadêmica do professor de línguas pode ser beneficiada (no sentido de ser inovada/ atualizada) ao ser adotada, nos estudos das línguas (como fizemos em relação ao latim), uma abordagem dos fenômenos da linguagem que não os reduza ao campo estritamente teórico-gramatical, mas que os considere inseridos no âmbito do devir, do histórico, do cultural e do socioideológico, isto é, como fenômenos intrinsecamente humanos.

Enfim, pelos resultados levantados em nossa pesquisa, estamos seguros de que a teoria dialógica representa, sim, uma alternativa exequível em sala de aula e sua aplicação traz ganhos heurísticos em termo de inovação e/ ou atualização do ensino-aprendizagem de língua latina, não só na URCA, mas também (adaptando-a a cada realidade) em outros cursos de Letras de outras universidades.

\section{Referências}

ALMEIDA, M. de F.; LEITE, F. de F. A teoria dialógica: uma experiência de inserção nas aulas de português no sertão cearense. Calidoscópio, São Paulo, v. 11, n. 1, p. 21-28, jan./abr. 2013.

ARRUDA, F. E. C. Dicionário e ensino de latim. In: MARTINS, E. S.; LEITE, F. de F. (Org.). Lingua, literatura e ensino: a pesquisa acadêmica no DLL/URCA. Maricá: Ponto da Cultura, 2010. p. 57-72.

ANGELO, C. M. P.; MENEGASSI, R. J. Perguntas de leitura na prática docente em sala de apoio. Revista Brasileira de Linguística Aplicada, Belo Horizonte, v. 14, n. 3, p. 661-688, 2014.

BAKHTIN, M. M. Para uma filosofia do ato responsável. Tradução de Valdemir Miotello e Carlos Alberto Faraco. São Carlos: Pedro \& João Editores, 2010.

BAKHTIN, M. M. O problema do texto na linguística, na filologia e em outras ciências humanas. In: BAKHTIN, M. M. Estética da criação verbal. 6. ed. Tradução de Paulo Bezerra. São Paulo: Martins Fontes, 2011a. p. 307-335.

BAKHTIN, M. M. Metodologia das ciências humanas. In: BAKHTIN, M. M. Estética da criação verbal. 6. ed. Tradução de Paulo Bezerra. São Paulo: Martins Fontes, 2011b. p. 393-410.

BAKHTIN, M. M. Questões de estilística no ensino da língua. Tradução, posfácio e notas de Sheila Grillo e Ekaterina Vólkova Américo; apresentação de Beth Brait; organização e notas da edição russa de Serguei Botcharov e Liudmila Gogotchvíli. São Paulo: Editora 34, 2013. 
BAKHTIN, M. M. (VOLOCHÍNOV, V. N.). Marxismo e filosofia da linguagem: problemas fundamentais do método sociológico na ciência da linguagem. 13. ed. Tradução de M. Lahud e Y. F. Vieira. São Paulo: Hucitec, 2009.

BRAGANÇA JÚNIOR, Á. A. Os provérbios medievais em latim e a apropriação da cultura laica pelo discurso religioso - algumas palavras. Mirabilia, Barcelona, n. 6, p. 101-127, jun./dez. 2006.

BRAIT, B. A palavra mandioca do verbal ao verbo-visual. Bakbtiniana, São Paulo, v. 1, n. 1, p. $142-160,1^{\circ}$ sem. 2009.

BRAIT, B. Análise e teoria do discurso. In: BRAIT, B. (Org.). Bakbtin: outros conceitos-chave. São Paulo: Contexto, 2010. p. 9-31.

BRAIT, B. Lições de gramatica do professor Mikhail M. Bakhtin. In: BAKHTIN, M. M. Questões de estilística no ensino da língua. Tradução, posfácio e notas de Sheila Grillo e Ekaterina Vólkova Américo; apresentação de Beth Brait; organização e notas da edição russa de Serguei Botcharov e Liudmila Gogotchvíli. São Paulo: Editora 34, 2013. p. 7-18.

BURKE, P. O latim: uma língua em busca de uma comunidade. In: BURKE, P. Linguagens e comunidades nos primórdios da Europa moderna. Tradução de Cristina Yamagami. São Paulo: Editora Unesp, 2010. p. 59-75.

FARACO, C. A. Linguagem \& diálogo: as ideias linguísticas do Círculo de Bakhtin. São Paulo: Parábola, 2009.

FARIA, E. Introdução à didática do Latim. Rio de Janeiro: Acadêmica, 1959.

FERNANDES, T. A tradução e o ensino do latim. 2010.159 f. Dissertação (Mestrado em Estudos da Tradução) - Universidade Federal de Santa Catarina, Florianópolis, 2010.

FREITAS, L. M. A. de. Uma coleção didática para o ensino de latim em análise. Revista Escrita, Rio de Janeiro, n. 15, p. 1-15, 2012.

FUNARI, P. P. A. A vida quotidiana na Roma antiga. São Paulo: Annablume, 2003.

GERALDI, J. W. A aula como acontecimento. São Carlos: Pedro e João Editores, 2010.

HECK, M. R. D. O ensino do latim no Brasil: objetivos, método e tradição. 2013. 35

f. Trabalho de Conclusão de Curso (Especialização em Letras: Português-latim) Universidade Federal do Rio Grande do Sul, Porto Alegre, 2013.

JONES, P. V.; SIDWELL, K. C. Aprendendo latim: textos, gramática, vocabulário, exercícios. Tradução e supervisão técnica de Isabella Tardin Cardoso, Paulo Sérgio de Vasconcellos; revisão técnica de Alessandro Rolim de Moura. São Paulo: Odysseus, 2012.

LEITE, F. de F. O latim em cartas do Cariri cearense: final do século XIX e início do século XX. João Pessoa: Ideia, 2009. 
LEITE, F. de F. Trabalhando com os sentidos de expressões latinas no gênero textual carta pessoal: sobre um corpus do Cariri cearense dos séculos XIX e XX. In: SIGET - SIMPÓSIO INTERNACIONAL DE ESTUDOS DE GÊNEROS TEXTUAIS, 6, 2011, Natal. Anais... Natal: UFRN, 2011. p. 1-9.

LEITE, F. de F. Inscrições em latim sob uma abordagem dialógica: um estudo no contexto do Cariri cearense. 2014. 210 f. Tese (Doutorado em Linguística) - Universidade Federal da Paraíba, João Pessoa, 2014.

LIMA, A. D. Uma estranha língua?: questões de linguagem e método. São Paulo: Editora da Unesp, 1995.

LONGO, G. Ensino de latim: problemas linguísticos e uso de dicionário. 2006. 105 f. Dissertação (Mestrado) - Faculdade de Ciências e Letras, Araraquara, Universidade Estadual Paulista, 2006.

MARANHÃO, S. de M. Reflexões sobre o ensino de língua latina em cursos superiores de letras modernas. Instrumento - Revista de estudo e pesquisa em educaşão, Juiz de Fora, v. 11, n. 1, p. 27-36, jan./jun. 2009.

MEDVIÉDEV, P. N. O método formal nos estudos literários: introdução crítica a uma poética sociológica. Tradução de Sheila Camargo Grillo e Ekaterina Vólkova Américo. São Paulo: Contexto, 2012.

MIOTI, C. M. O ensino do latim nas universidades públicas do estado de São Paulo e o método inglês reading latin: um estudo de caso. 2006. 145 f. Dissertação (Mestrado em Linguística) - Instituto de Estudos da Linguagem, Universidade Estadual de Campinas, Campinas, 2006.

OLIVEIRA, A. Considerações sobre a prática didática das línguas clássicas. Disponível em: <http://www.oocities.com/textossbec/oliveira.doc>. Acesso em: 20 nov. 2014. POSSENTI, S. Gêneros discursivos: Bakhtin vai à escola. In: ARANHA, S. D. de G.; PEREIRA, T. M. A.; ALMEIDA, M. de L. L. (Org.). Gêneros e linguagens: diálogos abertos. João Pessoa: Editora Universitária da UFPB, 2009. p. 9-19.

PUZZO, M. B. Revisitando questões de gramática e de ensino de um ponto de vista bakhtiniano. Bakbtiniana - Revista de Estudos do Discurso, São Paulo, v. 7, n. 1, p. 161-177, jan./jun. 2012.

QUEDNAU, L. R. Ensino de latim: discussão e propostas. Cadernos do IL, Porto Alegre, n. 42, p. 320-338, jun. 2011.

SANTOS SILVA, J. E. dos; LEITE, F. de F. Para uma nova abordagem do Latim. Crato: F. de F. L., 2012.

SOBRAL, A. Texto, discurso, gênero: alguns elementos teóricos e práticos. Nonada, Porto Alegre, v. 1, n. 15, p. 9-29, 2010. 
SOBRAL, A. U. Elementos sobre a formação de gêneros discursivos: a fase "parasitária" de uma vertente do gênero de autoajuda. 2006. 305 f. Tese (Doutorado em Linguística Aplicada e Estudos da Linguagem) - Pontifícia Universidade Católica de São Paulo, São Paulo, 2006.

WIERIX, H. Sawing Boards (from the Infancy of Christ series). Gravura. [s/d]. Disponível em: <http://www.mfa.org/collections/object/sawing-boards-from-the-infancyof-christ-series-87609>. Acesso em: 12 nov. 2014

ZOZZOLI, R. M. D. A noção de compreensão responsiva ativa no ensino e na aprendizagem. Bakhtiniana - Revista de Estudos do Discurso, São Paulo, v. 7, n. 1, p. 253-269, jan./jun. 2012.

Data de submissão: 04/01/2016. Data de aprovação: 15/07/2016. 